\title{
DESIGNING AN AUTONOMOUS SYSTEM FOR THE PURPOSE OF RECEIPT AND DISPATCH OF MATERIALS BASED ON MOBILE APPLICATION
}

\author{
Michal Siget \\ Technical university of Košice, Faculty of Mining, Ecology, Process Control and Geotechnologies, Institute of \\ Logistics and Transport, Park Komenského 14, 043 84, Kosice, Slovak Republic, EU, michal.siget@ gmail.com
}

Keywords: Information systems, programming, RFID, logistics

Abstract: The article deals with the design of an autonomous system for the purposes of receiving and dispensing material based on a mobile application. The article contains analysis of automatic identification technologies, methods of electronic data exchange and description of the system itself. The automatic identification systems (SAI) have great importance in increasing company's responsiveness, quality increase and cost reduction. These systems could be used within various areas of human activities from food processing industry through heavy industry to wholesale.

\section{Introduction}

The importance in managing all flows in the business is growing. Development of new technologies such as smart homes and industrial facilities, using drones for various activities, or Internet of Things (collectively named Industry 4.0) bring new methods of their management. With an expanding amount of goods, the data processing needs to be quicker and more effective. The use of technologies mentioned above is an excellent way of doing so.

\section{Methodology}

\subsection{Technologies used in automated identification systems}

The automatic identification systems (SAI) have great importance in increasing company's responsiveness, quality increase and cost reduction. These systems could be used within various areas of human activities from food processing industry through heavy industry to wholesale. Using them is required because of needs of improvement of logistics information systems. Automatic identification systems are systems meant to create, collect, and accelerate information processing and improve accuracy. These systems are being developed along with information technologies. Using SAI allows to process more information, it saves time by eliminating manual data processing and it minimizes impact of human factor as well [1].

Basic concept of these systems is creation and collecting information to ensure accurate data and automate related activities. Accordingly, it is possible to determine their key advantages: Increasing efficiency i.e. workers are able to do more work in the same time. Due to the automation of identification, the amount of administrative activity is considerably smaller, as the systems performs it. Since it is automatic system, it performs all task according to exact, predetermined procedures defined by developer without significant user intervention. Therefore, proportion of errors caused by human faults is minimal, as is the cost of sorting information manually. Another significant advantage is the improvement of customer services in the form of providing required information without delays.

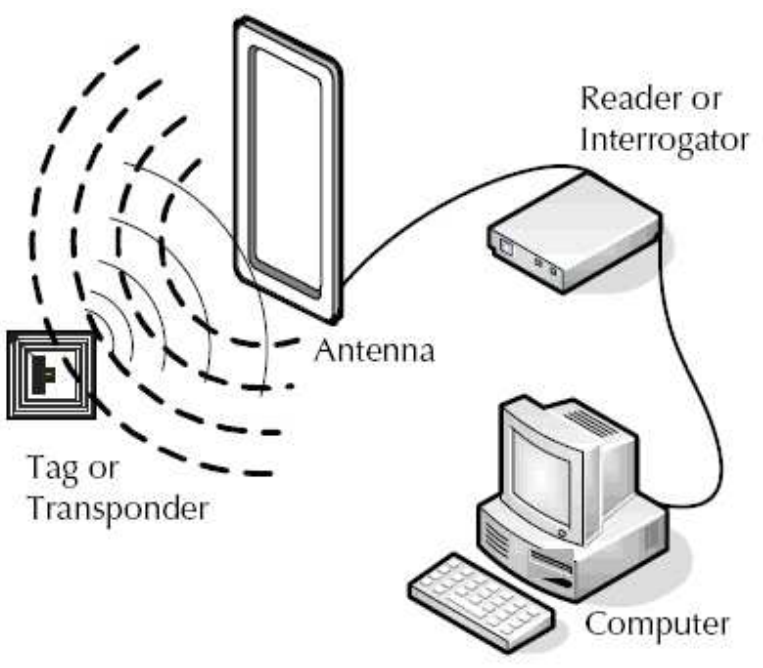

Figure 1 s RFID schema [2]

There are various technologies to process data. The most common technology are barcodes however, RFID technology is getting in the lead eliminating barcode imperfections and flaws such as sensitivity to printing quality, weather conditions, handling (Figure 1). Unlike barcodes, RFID chips do not require immediate proximity of chip and reader, and the date are read even if the reader is several meters away, and these two objects don't see each other [3]. 
DESIGNING AN AUTONOMOUS SYSTEM FOR THE PURPOSE OF RECEIPT AND DISPATCH OF MATERIALS BASED ON MOBILE APPLICATION

Michal Siget

\subsection{Electronic data interchange}

The use of electronic communication minimizes the need for manual information processing and allows the sending of structured messages from the sender's computer to the recipient's computer. In order to use this method of communication, it is necessary to provide hardware equipment (computer connected to the network), software, and operator communication services [1].

EDI-based data exchange uses structured files. These files have different formats and not every format is suitable for use in any conditions. The most common formats are:

.XML - The structure of such files is readable for both computers and humans. it is very similar to HTML, but HTML is used to display data (used when writing web pages) (Figure 2). The advantage of XML is its ability to simplify sharing, transfer availability and compatibility between different platforms because it stores data as text without formatting [3].

.JSON - a language for storing and transferring data in a structured form based on JavaScript programming language. It can be used in various other programming languages.

.CSV - data are separated by comma, or a predefined character. Similar to previous types, .CSV stores data as plain text without formatting, but compared to .XML or .JSON, .CSV files have a much simpler structure [4].

Electronic data exchange brings several advantages over the classical form. First and foremost, when you exchange data electronically, time and work are saved because specific information is not needed to be entered multiple times. Data exchange takes place almost immediately after it is sent, so the time it takes to physically move documents can be used in a different way. The fact that there is no need to rewrite the data several times reduces the possibility of a false entry. In addition, the possibility of an error caused by a carrier in the form of loss or destruction of a document is also minimized. Electronic data exchange also increases flexibility in responding to customer requests.

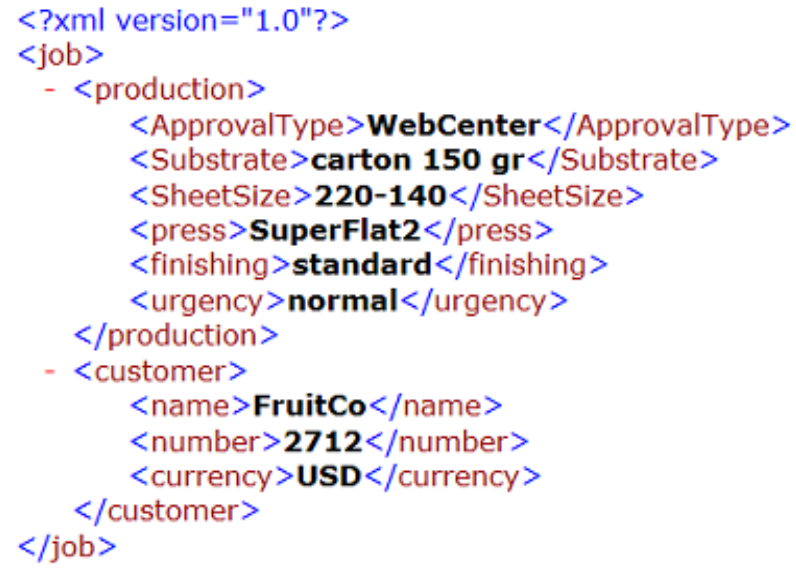

Figure 2.XML file structure [5]

\subsection{Project of system for receiving and dispatching materials}

The system is designed in MS Excel 2013. While the system works in newer versions of Excel, backward compatibility is not guaranteed as older versions may not support the features that were used to create this system.

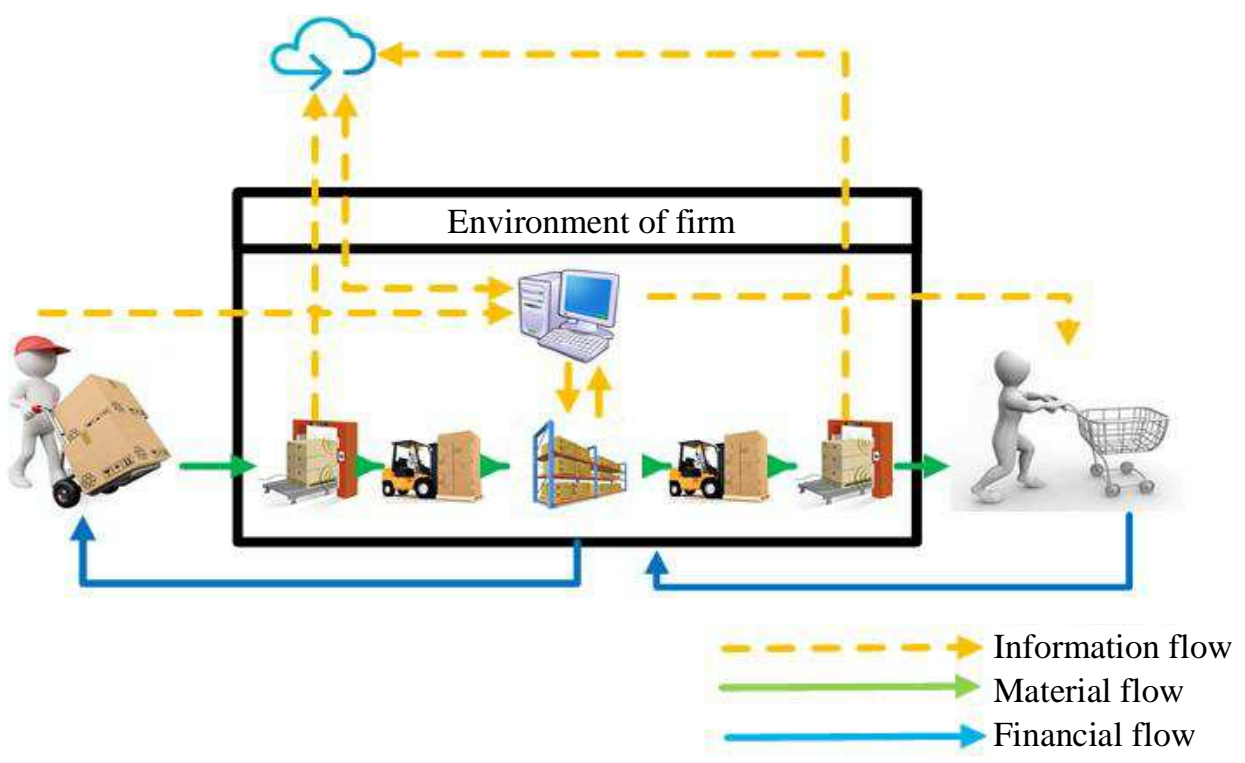

Figure 3 schema of the system 
DESIGNING AN AUTONOMOUS SYSTEM FOR THE PURPOSE OF RECEIPT AND DISPATCH OF MATERIALS BASED ON MOBILE APPLICATION

Michal Siget

The system (Figure 3, Figure 4) works with external data that can be stored on the local hard drive of a computer, server organization, or cloud server . In practice, the most used method of storing on a particular organization's server, because storing on the hard drive of the user's computer is impractical and the use of cloud services is costly, and reliability and security is not guaranteed. The proposed system works with data stored on the computer's hard drive. These data are automatically loaded into the appropriate databases when opened. In addition, the data can be updated as needed. When work with the system is completed, the external data is updated depending on the changes. The cloud is used only as the data carrier from the NFC card simulating a particular material palette to the computer when it is received or dispatched.

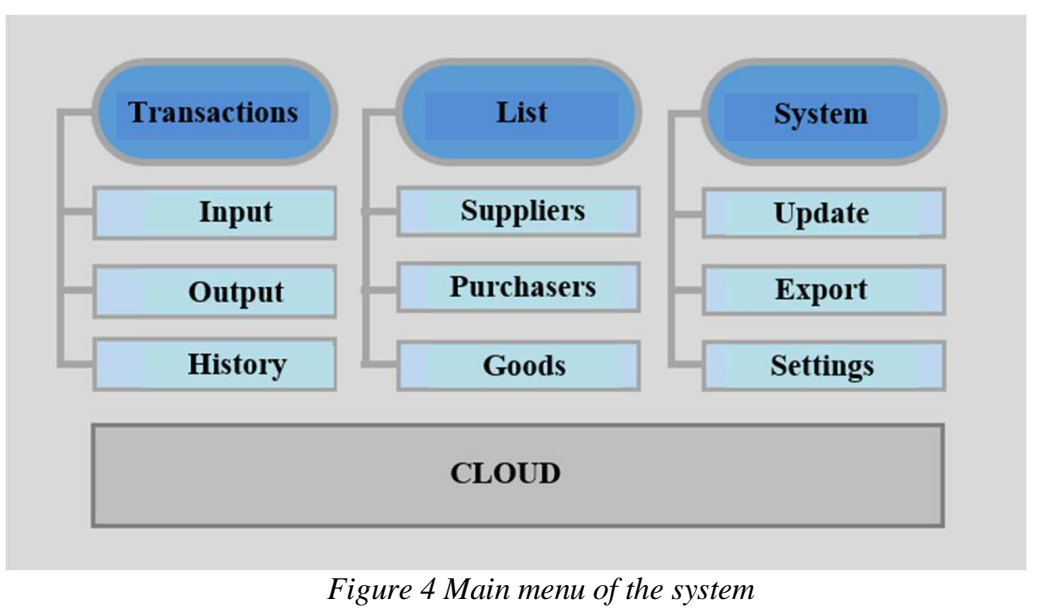

The system designed in this work uses NFC technology. There are many manufacturers and NFC reader types are within the market, but most require a USB cable to connect to a computer, which may be restrictive. This problem can be eliminated by a reader that can transmit data over a wireless network, whether using Bluetooth or WiFi.

Figure 5 shows the operation of the system. The first step is to pair the order with the delivery note. Subsequently, supplier data is added and the system starts loading NFC tag information and records it in the appropriate databases and updates the inventory status. In addition, it also archives all transactions and can generate the necessary documents.

\section{Conclusion}

The aim of the work was to design an autonomous information system in MS Excel environment using RFID technology, evaluate the efficiency and economic benefits of the proposed system.

The work includes a description of the system and its functioning to maintain its functionality. It uses NFC technology, which is significantly cheaper than RFID technology. However, it has some limitations that can be eliminated by further research.

Complete automation is possible to automate the individual processes to a great extent and, compared to the system proposed in previous work, the benefits of time saving, error minimization and barcode quality dependency are significant.

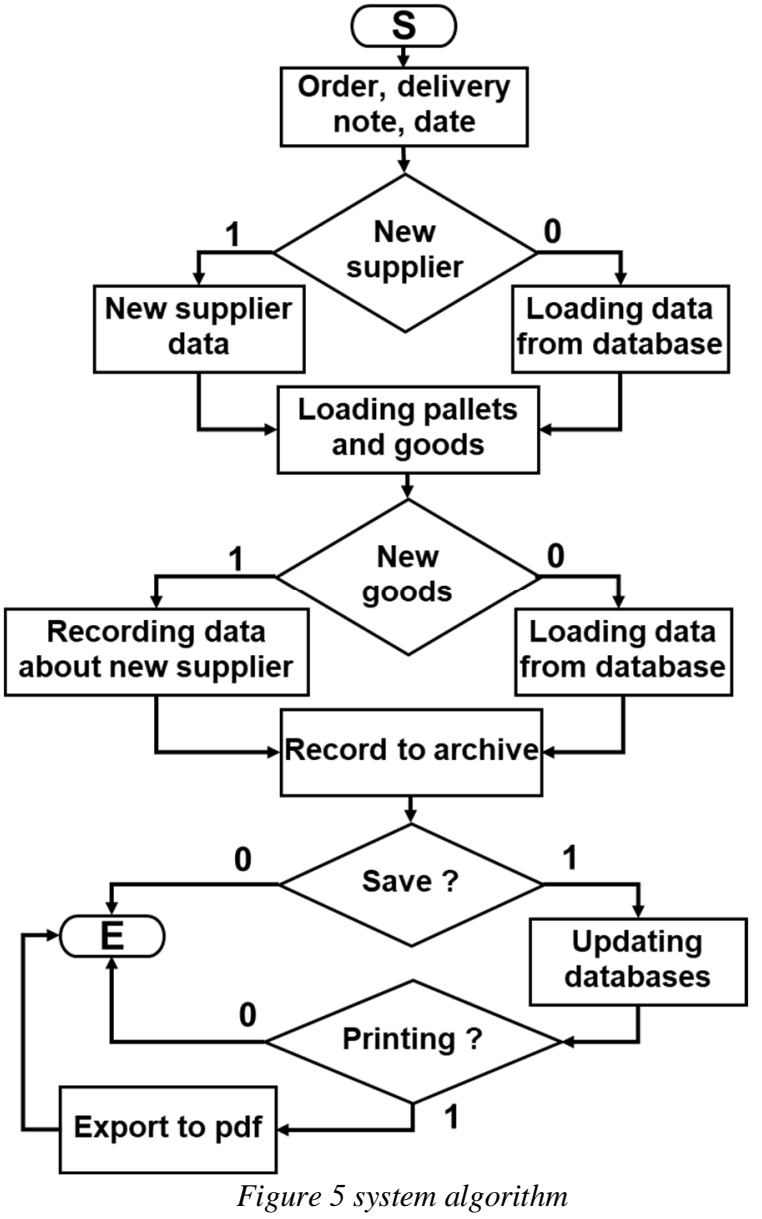




\section{References}

[1] BALOG, M., STRAKA, M.: Logistic Information Systems, Logistické informačné systémy, EPOS, pp. 208, 2005. (Original in Slovak)

[2] What is RFID?, [Online], Available: https://www.epcrfid.info/rfid [4.12.2018], 2018.

[3] ŠKAPA, R., KLAPALOVÁ, A.: Řízení zpětných toků, Management of reverse flows, Brno, Masarykova univerzita, 2011. (Original in Czech)

[4] What Is a CSV File, and How Do I Open It?, [Online], Available: https://www.howtogeek.com/348960/what -is-a-csv-file-and-how-do-i-open-it/ [3.12.2018], 2018.

[5] Introduction to XML, [Online], Available: https://www.w3schools.com/xml/xml_whatis.asp [3.12.2018], 2015.

\section{Review process}

Single-blind peer review process. 